\title{
Preliminary analytical study on seismic ductility demand of wood diaphragms
}

Dichuan Zhang, Robert Fleischman, Chang Shon

- School of Engineering

Abstract

A new seismic design methodology is being proposed for floor diaphragms for various types of construction materials including wood diaphragms. The new design methodology introduces a design acceleration to keep diaphragm elastic under design-basis earthquake using a mode superposition method. On top of this elastic design acceleration, a force reduction factor is proposed in the design methodology by considering available diaphragm ductility capacity and possible post-yielding strain hardening. This article presents an analytical study to examine the relationship between the force reduction factor and the ductility demand for the wood diaphragm using nonlinear dynamic time history analyses. The maximum allowable diaphragm design force reduction factor is determined using the analytical results and available wood diaphragm test data. Recommendations are provided for selection of the force reduction factor for the wood diaphragm for the new design methodology.

Original language

Pages (from-to)

Number of pages

Journal

Volume

Issue number

State

\section{English}

$104-115$

12

Advances in Structural Engineering

19

1

Published - Jan 12016

Zhang, D., Fleischman, R., \& Shon, C. (2016). Preliminary analytical study on seismic ductility demand of wood diaphragms. Advances in Structural Engineering, 19(1), 104-115. DOI: 10.1177/1369433215622874 